\title{
SEGURANÇA EM PLATAFORMAS DE PERFURAÇÃO E PRODUÇÃO DE PETRÓLEO OFFSHORE: APLICAÇÃO DA METODOLOGIA LEAN SIX SIGMA
}

\author{
SAFETY ON DRILLING AND PRODUCTION OIL PLATFORMS: APPLICATION OF LEAN SIX \\ SIGMA METHODOLOGY
}

\section{Felipe de Oliveira $\operatorname{Lima}^{1} \&$ Cláudia Rodrigues Teles ${ }^{2 *}$}

${ }^{12}$ Departamento de Engenharias e Tecnologia - Centro Universitário Norte do Espírito Santo - Universidade Federal do Espírito Santo, Rodovia BR 101 Norte, Km. 60, Bairro Litorâneo, CEP 29932-540, São Mateus

\section{${ }^{1}$ felipe.ol@hotmail.com ${ }^{* 2}$ claudia.teles@ufes.br}

\section{ARTIGO INFO.}

\section{Recebido em: 17.11.2021}

Aprovado em: 20.12.2021

Disponibilizado em: 02.02.2022

\section{PalavRas-ChaVe:}

Saúde e segurança do trabalho; Offshore; Lean Six Sigma; Ciclo DMAIC.

\section{KEYWORDS:}

Health and safety at work; Offshore; Lean Six Sigma; DMAIC Cycle.

*Autor Correspondente: Teles, C. R.

\section{RESUMO}

O pensamento enxuto ou Lean Six Sigma, pode ser definido como um método ou filosofia, que utiliza de ferramentas e técnicas visando otimizar, reduzir o número de falhas e por consequência aumentar a lucratividade de processos e produtos, sempre prezando pela qualidade. O presente trabalho objetiva aplicar a metodologia Lean Six Sigma para analisar pontos falhos nas medidas de saúde e segurança em plataformas de perfuração e produção de petróleo offshore e posteriormente a aplicação do ciclo DMAIC em tais pontos, para diminuir ainda mais a ocorrência de incidentes e acidentes nas plataformas. As informações referentes ao estudo foram levantadas via entrevistas com profissionais do setor petrolífero offshore, que buscaram identificar falhas nos processos relacionados à segurança em plataformas desde o pré-embarque até o desembarque. Como resultados, foi possível observar e propor melhorias para cinco pontos falhos, sendo destaque o baixo ou zero custo para as medidas apresentadas. Concluiu-se que a aplicação da metodologia Lean Six Sigma em plataformas é de grande valor e traz reduções nos riscos relacionados à saúde e segurança do trabalho através de melhorias apresentadas aos pontos falhos identificados.

\begin{abstract}
Lean thinking, or Lean Six Sigma, can be defined as a method or philosophy that uses tools and techniques to optimize, reduce the number of failures, and consequently increase the profitability of processes and products, always aiming for quality. The present research aims to apply the Lean Six Sigma methodology to analyze failure points in health and safety measures on offshore drilling and production platforms, and subsequently the application of the DMAIC cycle to those points to further decrease the occurrence of incidents/accidents on the platforms. The information for this study was collected via interviews with professionals in the offshore oil industry, who aimed to identify flaws in the processes related to safety on platforms from pre-embarkation to disembarkation. As results, it was possible to observe and propose improvements for five weak points, highlighting the low or zero cost for the measures presented. It was concluded that the application of the Lean Six Sigma methodology in platforms is of great value and brings reductions in risks related to occupational health and safety through improvements presented to the identified weak points.
\end{abstract}




\section{INTRODUÇÃO}

Nos dias de hoje, estamos diante de um mundo amplamente globalizado e competitivo, onde empresas estão cada vez mais interessadas em implementar ferramentas que otimizem seus processos, tornando-as mais competitivas. As empresas petrolíferas contam ainda, com a baixa do preço de venda da commodity há alguns anos, o que deixa o cenário ainda mais desafiador.

Recentemente, no Brasil, a produção de petróleo offshore tem se mostrado abundantemente mais efetiva que a produção onshore. Segundo o Instituto Brasileiro de Petróleo e Gás (IBP) com dados da Agência Nacional de Petróleo (ANP), em 2019, haviam 100 plataformas de perfuração e produção espalhadas pela costa brasileira, e esse número tende a aumentar com as novas rodadas de leilões (IBP, 2019). Por conta da evolução da produção offshore, principalmente dos campos do Pré-sal e o número crescente de plataformas, é necessário que as empresas estejam cada vez mais em dia com a Gestão de Saúde e Segurança do Trabalho (GSST) dentro das plataformas, afinal, há uma grande quantidade de colaboradores operando em cada plataforma.

Segundo Bôas (n.d.) a ISO 45001 é uma norma internacional para Sistema de Gestão de Saúde e Segurança Ocupacional (SGSSO), que se concentra na melhoria do desempenho da Saúde e Segurança do Trabalho (SST) de qualquer empresa. No Brasil, a saúde e segurança ocupacional tem como base de regimento, trinta e sete Normas Regulamentadoras (NR's), abrangendo estas, diferentes áreas da indústria e do trabalho, assim como situações específicas (Ministério do Trabalho, 2018a). As instituições públicas e privadas, os órgãos da administração pública e dos Poderes Legislativo e Judiciário que empreguem pessoas em regime CLT (consolidação das Leis do Trabalho) devem atender às NR's, uma vez que estas são de caráter mandatório.

A indústria petrolífera, em seu setor offshore, tem suas atividades regidas pela NR-37 (Segurança e Saúde em Plataformas de Petróleo), que apresenta inúmeras diretrizes de caráter administrativo, organizacional e de planejamento para a implantação de sistemas e medidas preventivas e de controle de SST no ambiente de trabalho, suas condições e processos produtivos associados (Ministério do Trabalho, 2018b). Segundo o item 37.1.1 da NR-37: "Esta Norma Regulamentadora - NR estabelece os requisitos mínimos de segurança, saúde e condições de vivência no trabalho a bordo de plataformas de petróleo em operação nas Águas Jurisdicionais Brasileiras - AJB”.

Segundo Moraes (2013), a medida em que se almeja mais bens e serviços, o número de plantas industriais relacionadas à extração, produção, armazenamento, transferência, manuseio e manipulação de produtos perigosos aumenta consequentemente. Esse aumento traz consigo também, um acréscimo no risco de acidentes. Ainda de acordo com Moraes (2013), o século $\mathrm{XX}$ foi marcado por desastres industriais e naturais, o que acarretou em prejuízo humano e material. Alguns acidentes no setor offshore, como o da plataforma Deepwater Horizon em 2010, no golfo do México e a plataforma FPSO Cidade de São Mateus em 2015, no Brasil, evidenciam o quão necessário se faz adotar processos de controle e elaboração de planos contingenciais de emergência.

Nesse contexto, projetos das instalações do setor petrolífero devem passar por uma análise de riscos, que consiste em um estudo a fim de identificar e avaliar os perigos e riscos. Tais análises 

metodologia Lean Six Sigma. Brazilian Journal of Production Engineering, 8(1), 49-60.

podem ser feitas através de algumas metodologias, como: Análise de Modo e Efeito de Falha (FMEA), Análise Preliminar de Riscos (APR) e Hazard and Operability Study (HAZOP) (Cardella, 2011). Uma outra metodologia possível de se utilizar é o Lean Six Sigma, que consiste em uma estratégia com objetivo de aumentar a lucratividade, redução do desperdício da não qualidade e consequentemente, a redução dos custos e melhoria do processo.

A atividade de produção de petróleo, no setor offshore é considerada contínua, complexa e perigosa por Moraes (2013). Contínua, pois o ciclo de produção ocorre 24 horas por dia, 7 dias da semana ao longo de todo o ano, sendo feito o revezamento das equipes de trabalho. Complexa, por conta de toda tecnologia envolvida por redes, o que impede se ter controle total sob o sistema. Perigoso, devido ao processamento constante de hidrocarbonetos que evaporam constantemente, o que gera atmosferas explosivas, aumentando assim, a possibilidade de acidentes com lesões, óbitos e até mesmo danos ao meio ambiente. Por conta disto, faz-se imprescindível que as empresas adotem estudos de análise de riscos.

A metodologia Lean visa otimizar processos utilizando a menor quantidade de recursos possível (tempo, equipamento, força de trabalho e espaço), sempre mantendo a qualidade e melhoria da cadeia de produção, juntamente com suas questões técnicas e operacionais, organização dos trabalhadores e gerenciamento de processos (Rachman et al., 2018).

Segundo Hashinaga (2019), as metodologias Lean Six Sigma já foram usadas em atividades do seguimento petrolífero, sendo observado estudos em 11 setores diferentes, sendo os mais aplicados: gerenciamento de reservatório, perfuração de poços e desenvolvimento de projetos de reservatórios. Ainda de acordo com o mesmo autor, com a queda no preço do barril de petróleo, as empresas precisaram buscar maneiras de diminuir custos de exploração, produção e otimização de processos da cadeia de petróleo e as metodologias Lean e Six Sigma foram aplicadas. A pesquisa de Hashinaga (2019) evidenciou 26 artigos que apresentam estudos onde são utilizadas as ferramentas Lean Six Sigma no setor petrolífero. O resultado foi positivo na maior parte das publicações, sendo os principais relatos de redução no tempo de ciclo e nos custos. Para os projetos de poços, houve uma redução de 3 para 2 anos no tempo necessário para o desenvolvimento do campo (Tønnessen et al., 2015). Segundo Chessa et al. (2013), com a padronização do design de topo de poço, houve redução de tempo e gasto para a construção de dois a seis meses.

Por ter um caráter multidisciplinar, a metodologia Lean Six Sigma tem se mostrado um caminho eficaz para a adoção de melhorias na área de SST. Isso, pois de acordo com a visão do método, que visa atingir a marca de defeitos próximo a zero, o Lean Six Sigma faz pela qualidade o mesmo que poderia realizar em termos de segurança nas empresas, onde não é aceitável que ocorra qualquer tipo de acidentes. Ou seja, o objetivo de eliminar todas as falhas de um produto ou processo também pode funcionar para reduzir riscos e acidentes. Lidando com o setor offshore, o Ciclo DMAIC pode ser aplicado dentro do SGSST das plataformas de petróleo, atuando diretamente desde o pré-embarque dos colaboradores até o cotidiano de trabalho nas plataformas, buscando soluções para as causas raízes dos acidentes e falhas ocorridas nestes processos. Desta forma, trazendo como resultado, operações e processos mais seguros, menos 
paradas durante os turnos de trabalho (algo que gera grande prejuízo às empresas, por conta do alto valor de afretamento das plataformas diariamente) e um ambiente de trabalho salubre.

Este trabalho visa como objetivo principal, analisar as atividades da cadeia de petróleo offshore, com foco nas questões relacionadas à saúde e segurança do trabalho nas plataformas de perfuração e exploração. Além disso, buscou-se entender as medidas de segurança necessárias desde o pré-embarque até o desembarque, abrangendo as principais atividades laborais, e então aplicar o ciclo DMAIC em tais medidas, a fim de, minimizar ainda mais os riscos de ocorrência de acidentes.

\section{METODOLOGIA}

O trabalho foi desenvolvido em duas etapas:

Na primeira etapa, foi realizada uma revisão sistemática da literatura, onde foi identificada a problemática do petróleo a cunho global e nacional, com foco no setor offshore, saúde e segurança no trabalho no setor petrolífero, o modelo Lean Six Sigma, suas ferramentas e técnicas, neste, com foco para o ciclo DMAIC.

$\mathrm{Na}$ segunda etapa, foram realizadas entrevistas com profissionais do setor petrolífero offshore, via formulários pré-elaborados, buscando identificar os processos relacionados à segurança em plataformas e, posteriormente, apresentadas as melhores maneiras de se aplicar o ciclo DMAIC detalhadamente em cada ponto falho observado.

Para elaborar as entrevistas, foi realizada uma análise da NR-37 (Segurança e Saúde em Plataformas de Petróleo), objetivando encontrar indicadores chave que são ligados aos processos de segurança nas plataformas de petróleo.

O intuito de realizar a entrevista, foi identificar pontos falhos ligados aos processos de segurança adotados nas plataformas de petróleo. Feito isso, o próximo passo da pesquisa foi iniciar a implementação da ferramenta Ciclo DMAIC buscando como resultados, soluções para reduzir ainda mais a taxa de acidentes no setor offshore.

De modo a tornar mais fácil a compreensão da metodologia, foi elaborado um fluxograma de atividades (Figura 1), que consiste na exposição das etapas que compuseram a pesquisa.

Figura 1. Fluxograma de atividades de execução da pesquisa.

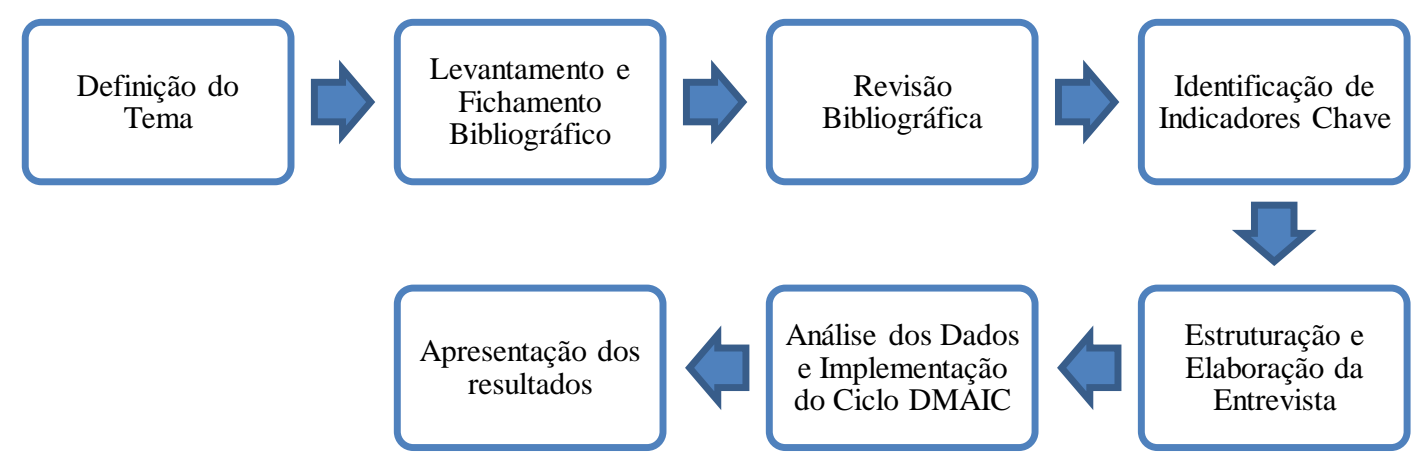

Fonte: Autores (2021).

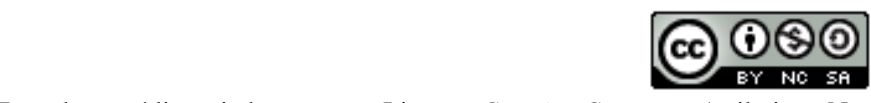



metodologia Lean Six Sigma. Brazilian Journal of Production Engineering, 8(1), 49-60.

Na primeira etapa do Ciclo DMAIC, Define, os KPI's são utilizados. Como já citado anteriormente, as empresas utilizam um ou mais indicadores (Key Performance Indicators), que são focados nas questões mais cruciais e críticas para que o processo / produto tenha um desempenho satisfatório, conseguindo atingir seus objetivos (Parmenter, 2007).

Dando sequência, na segunda etapa, Measure, utiliza-se o Diagrama de Causa e Efeito, popularmente conhecido como Diagrama de Ishikawa ou Espinha de Peixe, que consiste em uma ferramenta gráfica aplicada usualmente no gerenciamento e controle de qualidade em diferentes processos. (Peinado \& Graeml, 2007).

Já para a terceira etapa, Analyse, o método utilizado é conhecido como "Análise dos Porquês", que é uma ferramenta que auxilia a identificar a causa primária de situações indesejadas, desenvolvida por Taiichi Ohno, do Sistema de Produção Toyota (Bicheno, 2006).

Por fim, na quarta etapa, improve, é utilizado a ferramenta $5 \mathrm{~W} 2 \mathrm{H}$, que de acordo com Behr et al. (2008) a definem como "uma maneira de estruturarmos o pensamento de uma forma bem organizada e materializada antes de implantarmos alguma solução no negócio".

As entrevistas foram realizadas via formulários, através da plataforma Google Forms. As perguntas tiveram um padrão de respostas objetivas e/ou discursivas. Cada entrevistado respondeu de forma individual.

Importante salientar que o intuito de aplicar a entrevista à profissionais da área, atuantes em plataforma de petróleo offshore, consiste na análise das respostas e identificação dos pontos falhos nos processos de HSSE das mesmas. A partir dessa etapa, aplicar o Ciclo DMAIC, a fim de apresentar melhorias para tais pontos. A seguir, apresenta-se na Tabela 1, as perguntas que foram utilizadas para as entrevistas:

Tabela 1. Lista de Perguntas Para Entrevista

\begin{tabular}{|c|c|}
\hline Pergunta & Tipo de Resposta \\
\hline 1. O diálogo diário de segurança (DDS) ocorre de fato todos os dias? & Sim ou não \\
\hline 2. A análise preliminar de riscos (APR) é realizada antes de qualquer atividade? & Sim ou não \\
\hline $\begin{array}{l}\text { 3. Os colaboradores utilizam corretamente todos os equipamentos de proteção } \\
\text { individual (EPI's) necessários? }\end{array}$ & Sim ou não \\
\hline 4. Você saberia utilizar as rotas de fuga da plataforma, caso necessário? & Sim ou não \\
\hline 5. Há na plataforma simulações periódicas da utilização das rotas de fuga? & Sim ou não \\
\hline $\begin{array}{l}\text { 6. Existe uma Comissão Interna de Prevenção de Acidentes (CIPA) atuante na } \\
\text { empresa? }\end{array}$ & Sim ou não \\
\hline 7. Você sabe quais funcionários compõem a CIPA? & Sim ou não \\
\hline $\begin{array}{l}\text { 8. Os colaboradores têm as certificações exigidas para operar em plataformas? (NR's } \\
\text { por exemplo) }\end{array}$ & Sim ou não \\
\hline 9. Existe um mapa de risco? & Sim ou não \\
\hline 10. Os colabores costumam relatar riscos observados? & Sim ou não \\
\hline 11. Quando riscos são relatados, a empresa costuma corrigi-los de maneira rápida? & Sim ou não \\
\hline $\begin{array}{l}\text { 12. Você vê um ou mais pontos relacionados ao HSSE (Saúde, Segurança E Meio } \\
\text { Ambiente) da plataforma que poderiam ser aprimorados? }\end{array}$ & Discursiva \\
\hline $\begin{array}{c}\text { 13. Em relação aos acidentes / incidentes, estes ocorrem com frequência? Quais } \\
\text { medidas a empresa toma diante desta situação? }\end{array}$ & Discursiva \\
\hline $\begin{array}{l}\text { 14. O sistema de gestão de segurança e saúde do trabalho (nesta plataforma) é baseado } \\
\text { em qual(is) norma(s)? Ex.: ISO } 45001\end{array}$ & Discursiva \\
\hline $\begin{array}{l}\text { 15. A empresa possui indicadores de desempenho em segurança e saúde no trabalho? } \\
\text { Caso sim, sabe dizer qual(is)? }\end{array}$ & Discursiva \\
\hline
\end{tabular}

Fonte: Autores (2021). 

metodologia Lean Six Sigma. Brazilian Journal of Production Engineering, 8(1), 49-60.

\section{RESUltados E Discussão}

Tendo sido explorado a importância da saúde e segurança no trabalho e como o ciclo DMAIC pode auxiliar na melhoria de processos, o próximo passo é estruturar e aplicá-lo na temática em estudo, buscando minimizar a ocorrência de atos inseguros, incidentes e até mesmo acidentes em plataformas de petróleo offshore.

\section{DEFINE}

Para a definição da temática levou-se em consideração o fato de que o setor petrolífero de uma forma geral já apresenta altos riscos de acidentes de grandes proporções, tanto para os colaboradores, quanto para o meio ambiente em si. Em adição a isto, as plataformas de petróleo offshore, contam ainda com o fato de estarem isoladas em alto mar, o que gera uma dificuldade ainda maior para os colaboradores escaparem em caso de algum acidente.

Foram então convidados três profissionais atuantes em plataformas de petróleo offshore para responderem à entrevista de forma individual, para que seja possível identificar pontos falhos nos processos de segurança das plataformas e apontar possíveis melhorias para os mesmos.

Para a elaboração da entrevista, foram levados em consideração diversos KPI's relacionados ao HSSE, NR's e SGSST das plataformas.

\section{MEASURE}

A entrevista foi respondida por três profissionais, sendo todos engenheiros de petróleo e dois destes, graduados pela Universidade Federal do Espírito Santo. Os dados colhidos são referentes a três diferentes empresas atuantes no setor offshore e para maior confidencialidade, as mesmas não terão divulgados seus respectivos nomes.

Através da análise das respostas obtidas é possível observar 5 pontos falhos que serão apresentados a seguir através do Diagrama de Ishikawa da Figura 2:

Figura 2. Diagrama de Ishikawa com Dados da Entrevista

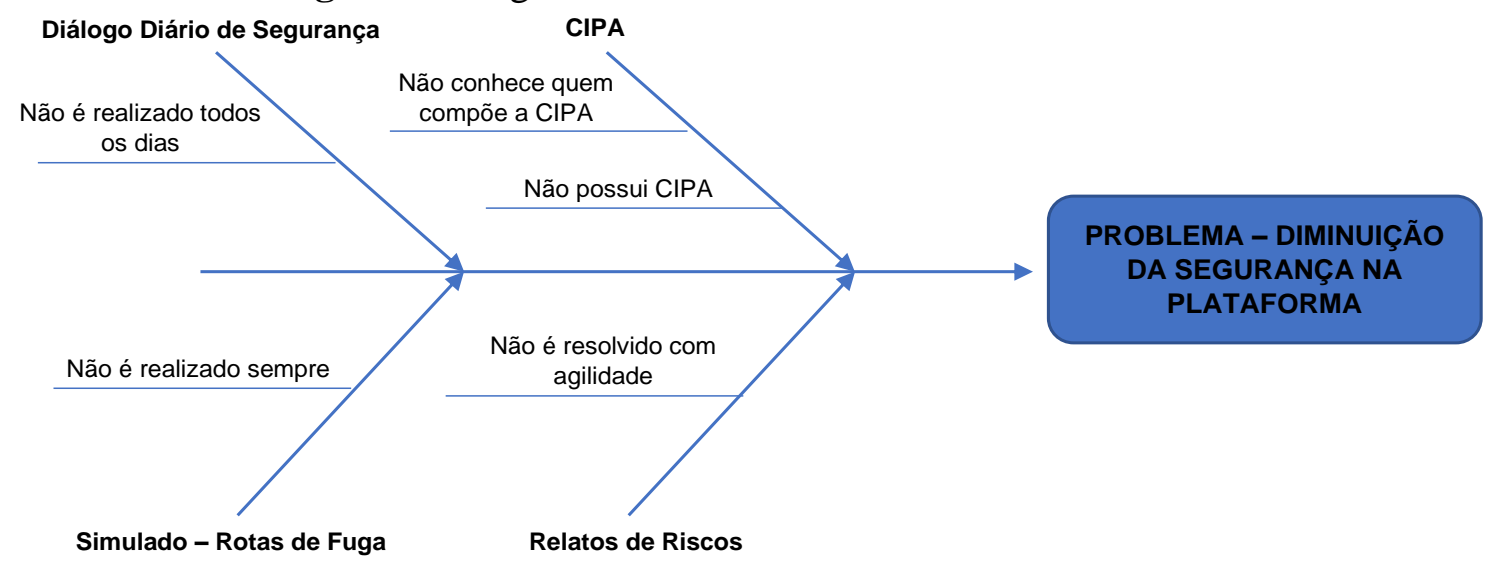

Fonte: Autores (2021).

Analisando o Diagrama de Ishikawa, ficam evidentes 4 áreas com pontos falhos, o que automaticamente fragiliza a segurança das plataformas. Desta forma, sendo definidos os primeiros pontos a serem trabalhados com o Ciclo DMAIC para buscar uma efetividade ainda maior para as questões relacionadas ao HSSE das plataformas. 

metodologia Lean Six Sigma. Brazilian Journal of Production Engineering, 8(1), 49-60.

Tratando-se das perguntas discursivas 12 a 15 da entrevista, destacam-se alguns pontos que chamaram a atenção, que merecem ser analisados e implantados para obter uma segurança ainda maior. De acordo com um dos entrevistados: “...um ponto de aprimoramento deve ser a sinalização de zonas de riscos devido à corrosão de contra corpos, por exemplo.” Esse ponto ocorre por algumas plataformas já estarem ativas a um grande período de tempo e por conta da alta incidência de corrosão causada pela maresia, os contra corpos acabam se deteriorando, sendo de extrema importância sinalizar como zona de risco ou até mesmo providenciar a substituição dos mesmos com certa periodicidade.

Outro ponto interessante de se destacar foi citado por outro entrevistado: "A ação sobre observações de segurança poderiam ser mais imediatas nas plataformas em geral, além disso, uma percepção dentro da área de operação offshore, onde muitos profissionais são especialistas nos seus setores, no entanto por vezes não possuem uma visão interdisciplinar dos diferentes processos, operações, normalidades de outros setores/departamentos." Essa questão é de suma importância, disseminar conhecimentos gerais, bem como operações rotineiras e não rotineiras para todos envolvidos numa plataforma, aumentaria a percepção de risco para todos os integrantes da plataforma, desta forma, garantindo percepções mais rápidas de situações de risco.

ANALYSE

Após a etapa Measure, a Tabela 2 apresenta os principais problemas e suas consequências identificados:

Tabela 2. Principais Problemas

\begin{tabular}{|c|c|}
\hline Problemas & Consequências \\
\hline $\begin{array}{l}\text { DDS não é realizado } \\
\text { todos os dias }\end{array}$ & $\begin{array}{l}\text { Aumenta os riscos de maneira geral, devido à falta de comunicação entre os } \\
\text { colaboradores. Os mesmos não terão ciência de todas as atividades que serão } \\
\text { desenvolvidas naquele turno, aumentando as chances de algum acidente ocorrer. }\end{array}$ \\
\hline $\begin{array}{l}\text { Simulado de rotas } \\
\text { de fuga não são } \\
\text { realizados sempre }\end{array}$ & $\begin{array}{l}\text { A falta dos simulados gera um risco alto, pois os colaboradores não saberão utilizar } \\
\text { as rotas de fuga com eficácia ou até mesmo não terão conhecimento da localização da } \\
\text { rota de fuga em caso de uma emergência. }\end{array}$ \\
\hline $\begin{array}{l}\text { Relatos de riscos } \\
\text { não são resolvidos } \\
\text { com agilidade }\end{array}$ & $\begin{array}{l}\text { Quando riscos são relatados, é de suma importância que sejam tratados com a maior } \\
\text { agilidade possível, para evitar que algum incidente ou acidente venha a acontecer, } \\
\text { colocando os colaboradores em risco. }\end{array}$ \\
\hline $\begin{array}{l}\text { Não possui CIPA / } \\
\text { não conhecem quem } \\
\text { compõe a CIPA }\end{array}$ & $\begin{array}{l}\text { A presença da CIPA na plataforma é indispensável, pois os colaboradores que a } \\
\text { compõe, atuam como voz ativa de todos os colaboradores da plataforma. / Conhecer } \\
\text { os membros é indispensável, pois assim é possível acompanhar as atividades da } \\
\text { CIPA e também saber a quem relatar alguma eventualidade. }\end{array}$ \\
\hline
\end{tabular}

Fonte: Autores (2021).

Com os problemas definidos, é possível então utilizar a ferramenta da análise dos porquês, com intuito de identificar as possíveis causas raízes dos problemas encontrados, com isso, sendo possível apresentar pontos de melhorias para tais causas. A seguir, nas Figuras 3, 4, 5, 6 e 7 serão apresentadas as análises dos porquês: 

metodologia Lean Six Sigma. Brazilian Journal of Production Engineering, 8(1), 49-60.

Figura 3. Primeira Análise dos Porquês
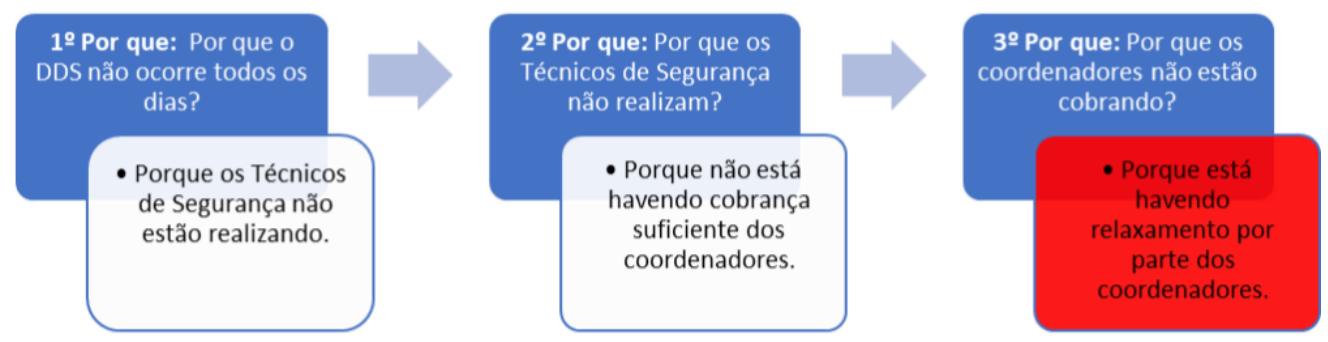

Fonte: Autores (2021).

Figura 4. Segunda Análise dos Porquês
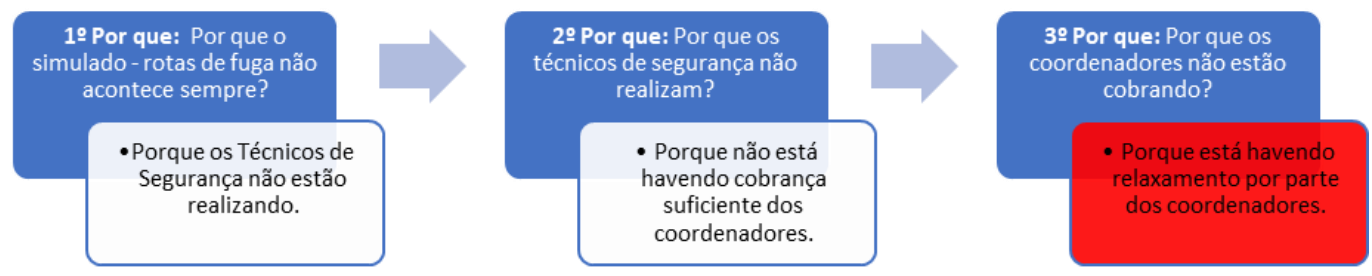

Fonte: Autores (2021).

Figura 5. Terceira Análise dos Porquês
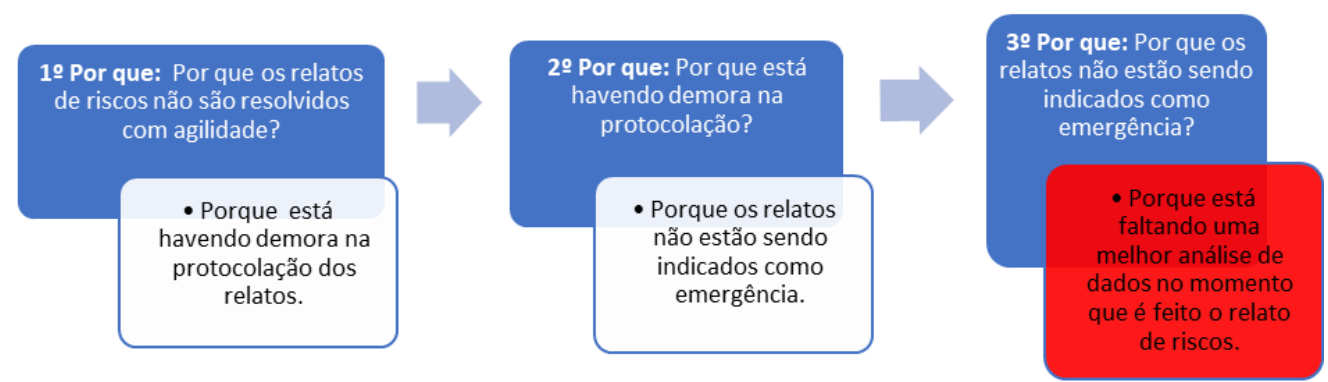

Fonte: Autores (2021).

Figura 6. Quarta Análise dos Porquês
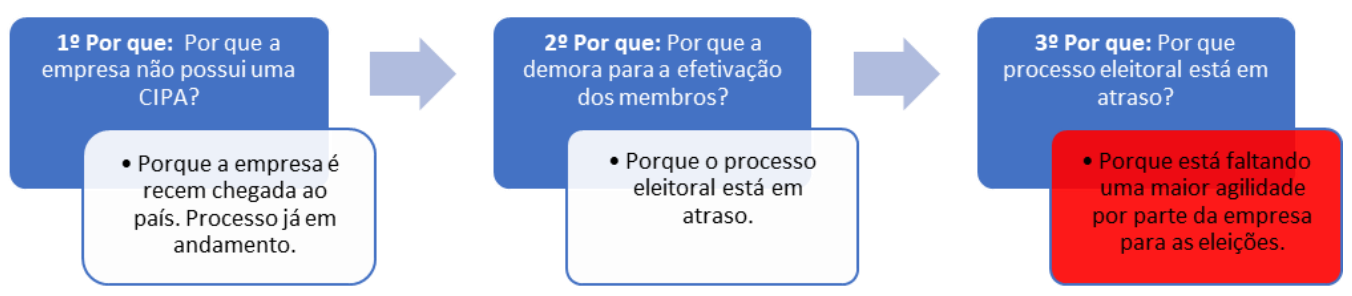

Fonte: Autores (2021).

Figura 7. Quinta Análise dos Porquês
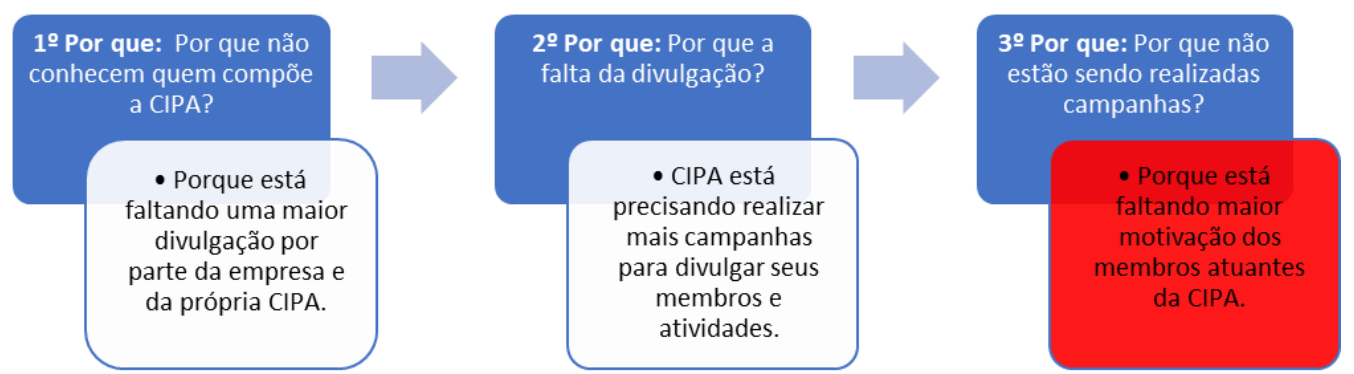

Fonte: Autores (2021).

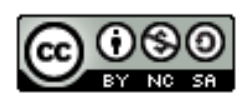



metodologia Lean Six Sigma. Brazilian Journal of Production Engineering, 8(1), 49-60.

É possível então observar as possíveis causas raízes dos problemas mencionados através dos quadros de respostas destacados em vermelho. Logo, dando sequência à fase Analyse, serão levantadas as melhores maneiras de "contra atacar" essas causas, criando oportunidades de melhoria para o processo como um todo.

Para a primeira questão levantada: “Por que o DDS não ocorre todos os dias?", é proposto que os coordenadores tenham uma maior cobrança para com os técnicos de segurança, com intuito de que o DDS seja de fato realizado diariamente. Inclusive, destaca-se a importância da participação ativa também dos coordenadores e dos colaboradores. Uma boa prática a ser considerada é a de sempre dar voz aos colaboradores para que estes informem a necessidade de algum ponto de melhoria, ou até mesmo algum equipamento que esteja necessitando comprar ou reparar (um talabarte com defeito ou em falta, por exemplo), para que as atividades sejam realizadas com maior segurança.

Para a segunda questão levantada: "Por que o simulado - rotas de fuga não acontece sempre?", propõe-se, como para a primeira situação, que os coordenadores tenham uma maior cobrança com os técnicos de segurança, para que os mesmos venham a realizar os simulados de rota de fuga ao menos uma vez por escala com o turno do dia e com o turno da noite. Este simulado tem extrema importância, pois em caso de uma situação de emergência, é necessário que todos a bordo da plataforma saibam utilizar as rotas de fuga, ou seja, praticando sempre, se tornará algo rotineiro para os colaboradores e mesmo sob toda tensão de uma emergência, estes conseguirão utilizar as rotas com naturalidade.

Para a terceira questão: "Por que os relatos de risco não são resolvidos com agilidade?", chegouse à conclusão de que é necessário otimizar o processo de coleta de relatos. Seria interessante que, toda vez que um colaborador for relatar algum risco, de imediato seja realizada uma análise prévia da situação, caracterizando em graus de periculosidade, indo de baixo a alto risco. Com esse detalhamento é possível estabelecer prazos condizentes para cada situação, sendo relatos de alto risco sanados com emergência, com o menor tempo possível, e relatos de baixo risco, tendo um tempo maior para a resolução da problemática.

Tratando-se da quarta questão: "Por que a empresa não possui uma CIPA?", para o caso específico citado na entrevista, a empresa é recém chegada ao Brasil e o processo de criação da CIPA já está em execução. Porém, ainda sim é importante destacar o quão necessário é a empresa despender mais energia no processo. Realizar uma ampla divulgação da CIPA e suas funções, destacando sempre a importância de ter a comissão mais ativa possível e como isso traz inúmeros benefícios aos colaboradores. Salientando que essa situação se aplica também à todas empresas que não possuem uma CIPA ainda ou que com o tempo foi sendo deixada de lado.

Por fim, referente à quinta questão: "Por que não conhecem quem compõe a CIPA?", é proposto que seja realizada uma campanha por parte da empresa, convidando palestrantes da área de HSSE para realizar uma capacitação motivacional com os atuais membros da CIPA, visando que tais membros renovem as energias da gestão atual. Como resultado, espera-se que essa motivação adquirida gere como frutos novas campanhas realizadas pela CIPA, com objetivo de destacar as atividades realizadas pela comissão, a importância de conhecer os membros 

metodologia Lean Six Sigma. Brazilian Journal of Production Engineering, 8(1), 49-60.

atuantes, para saber a quem procurar para relatar uma eventualidade e por consequência atrair novos colaboradores para se integrarem à comissão.

\section{IMPROVE}

Tendo sido apresentado até o momento os problemas enfrentados, feita a análise dos dados coletados, definidas as possíveis causas raízes e contramedidas para otimizar os processos, nesta etapa inicia-se de fato a ação prática, ou seja, implementar as melhorias definidas.

Será então, utilizada a técnica $5 \mathrm{~W} 2 \mathrm{H}$, apresentada anteriormente. Importante salientar que a Tabela 3 a seguir apresentará resultados estipulados, visto que a pesquisa não tem como intuito a aplicação real das melhorias, mas sim apresentar à comunidade que é possível aumentar ainda mais a segurança nas plataformas offshore através da aplicação do Ciclo DMAIC.

Tabela 3. 5W2H - Aumentar Segurança em Plataformas Offshore

\begin{tabular}{|c|c|c|c|c|c|c|}
\hline O que? & Quem? & Quando? & Onde? & Como? & Porque? & Quanto? \\
\hline $\begin{array}{l}\text { Realizar } \\
\text { DDS }\end{array}$ & $\begin{array}{l}\text { Técnicos de } \\
\text { segurança e } \\
\text { coordenadores }\end{array}$ & Diariamente & $\begin{array}{l}\text { Local de } \\
\text { reunião } \\
\text { antes do } \\
\text { turno } \\
\text { iniciar }\end{array}$ & $\begin{array}{l}\text { Maior cobrança } \\
\text { por parte dos } \\
\text { coordenadores }\end{array}$ & $\begin{array}{l}\text { Todos ficarem } \\
\text { cientes das } \\
\text { atividades do dia } \\
\text { para maior } \\
\text { segurança }\end{array}$ & $\mathrm{R} \$ 0$ \\
\hline $\begin{array}{l}\text { Realizar } \\
\text { simulados - } \\
\text { rota de fuga } \\
\text { sempre }\end{array}$ & $\begin{array}{l}\text { Técnicos de } \\
\text { segurança }\end{array}$ & $\begin{array}{c}\text { Uma vez a } \\
\text { cada escala } \\
\text { com o turno } \\
\text { do dia e da } \\
\text { noite }\end{array}$ & $\begin{array}{l}\text { Rotas de } \\
\text { fuga da } \\
\text { plataforma }\end{array}$ & $\begin{array}{l}\text { Maior cobrança } \\
\text { por parte dos } \\
\text { coordenadores }\end{array}$ & $\begin{array}{l}\text { Colaboradores } \\
\text { saberem utilizar } \\
\text { as rotas de fuga } \\
\text { com } \\
\text { naturalidade }\end{array}$ & $\mathrm{R} \$ 0$ \\
\hline $\begin{array}{l}\text { Otimizar } \\
\text { coleta de } \\
\text { relatos de } \\
\text { risco }\end{array}$ & $\begin{array}{c}\text { Técnicos de } \\
\text { segurança e } \\
\text { coordenadores }\end{array}$ & $\begin{array}{l}\text { Duas } \\
\text { semanas } \\
\text { para } \\
\text { estruturar }\end{array}$ & $\begin{array}{l}\text { Sala dos } \\
\text { Técnicos } \\
\text { de } \\
\text { segurança }\end{array}$ & $\begin{array}{c}\text { Caracterizar } \\
\text { relatos por grau } \\
\text { de } \\
\text { periculosidade e } \\
\text { definir tempo de } \\
\text { solução de cada } \\
\text { via grau } \\
\text { definido }\end{array}$ & $\begin{array}{l}\text { Diminuir } \\
\text { demora para } \\
\text { sanar riscos } \\
\text { relatados }\end{array}$ & $\begin{array}{l}\text { Custo a } \\
\text { depender } \\
\text { da } \\
\text { necessidade } \\
\text { de cada } \\
\text { risco } \\
\text { relatado }\end{array}$ \\
\hline $\begin{array}{l}\text { Criação da } \\
\text { CIPA }\end{array}$ & $\begin{array}{l}\text { Representantes } \\
\text { da empresa e } \\
\text { dos } \\
\text { colaboradores }\end{array}$ & $\begin{array}{l}\text { Um mês para } \\
\text { realizar } \\
\text { divulgação e } \\
\text { eleições }\end{array}$ & Plataforma & $\begin{array}{l}\text { Campanha para } \\
\text { atrair candidatos } \\
\text { e após realizar } \\
\text { eleição }\end{array}$ & $\begin{array}{c}\text { Extrema } \\
\text { importância a } \\
\text { presença de uma } \\
\text { CIPA ativa na } \\
\text { plataforma }\end{array}$ & $\begin{array}{c}\text { Baixo } \\
\text { custo, } \\
\text { apenas } \\
\text { impressão } \\
\text { de } \\
\text { panfletos e } \\
\text { guias de } \\
\text { votação }\end{array}$ \\
\hline $\begin{array}{l}\text { Divulgação } \\
\text { dos } \\
\text { membros } \\
\text { que } \\
\text { compõem a } \\
\text { CIPA }\end{array}$ & $\begin{array}{c}\text { Membros } \\
\text { atuais da CIPA }\end{array}$ & $\begin{array}{l}\text { De imediato, } \\
\text { mantendo } \\
\text { por toda a } \\
\text { gestão }\end{array}$ & Plataforma & $\begin{array}{l}\text { Palestrantes de } \\
\text { HSSE para } \\
\text { motivar } \\
\text { membros da } \\
\text { CIPA a } \\
\text { realizarem } \\
\text { campanhas de } \\
\text { divulgação }\end{array}$ & $\begin{array}{c}\text { Colaboradores } \\
\text { saberem quem } \\
\text { procurar para } \\
\text { relatar } \\
\text { eventualidades e } \\
\text { se interessarem } \\
\text { em ingressar } \\
\text { para a CIPA }\end{array}$ & $\begin{array}{c}\text { Baixo } \\
\text { custo, } \\
\text { apenas da } \\
\text { contratação } \\
\text { dos } \\
\text { palestrantes }\end{array}$ \\
\hline
\end{tabular}

Fonte: Autores (2021).

Os dois pontos levantados nas entrevistas pelos engenheiros, também são muito importantes de serem levados em consideração e aplicados. $\mathrm{O}$ fato de sinalizar contra corpos como zona de risco ou até mesmo providenciar a substituição dos mesmos com certa periodicidade é uma questão muito importante de ser tratada. Logo, é necessária atenção por parte dos técnicos de segurança para realizar as tratativas merecidas. 

metodologia Lean Six Sigma. Brazilian Journal of Production Engineering, 8(1), 49-60.

E quanto à questão de disseminar conhecimentos gerais para todos da plataforma com intuito de se obter percepções de risco de maneira mais rápida, também muito importante, é necessário planejar treinamentos com profissionais capacitados, visando passar a todos o funcionamento geral da plataforma e de cada processo. Sendo explorado quais são os riscos que cada atividade oferece e maneiras simples de identificar riscos, todos na plataforma estarão com mais atenção para estes pontos e com isso obtém-se uma percepção mais rápida de riscos.

\section{CONTROL}

Com as melhorias implementadas às plataformas, espera-se que seja possível observar uma melhoria significativa nas questões relacionadas ao HSSE. Porém, para uma mudança ser de fato uma melhoria, deve se manter ao longo do tempo, de forma contínua.

Para isso, é necessário realizar um acompanhamento pós aplicação das melhorias, a fim de se ter um controle sob o processo, para garantir que as novas metodologias sejam seguidas à risca e não seja apenas algo momentâneo. Utilizam-se algumas ferramentas de controle como: Checklists de acompanhamento (para garantir que o DDS está sendo realizado de fato todos os dias e os simulados de rota de fuga uma vez a cada escala com o turno da noite e com o turno do dia, por exemplo) e estatísticas (observar se houve de fato redução no tempo de espera de resolução dos riscos de alta periculosidade relatados, por exemplo). Com isso é possível acompanhar o desempenho geral das melhorias de cada processo (Udemy, [n.d.]).

É também recomendado, que alguns meses após as melhorias serem aplicadas, realizar uma nova medição do processo, a fim de se obter um comparativo entre os dados anteriores e os atuais, provando ou não o sucesso da aplicação do Ciclo DMAIC e caso necessário, realizar ajustes merecidos.

\section{ConCluSÃo}

Da análise dos resultados, ficou evidente que a aplicação do Ciclo DMAIC nos pontos falhos identificados através das entrevistas, propiciou melhorias para cada um dos mesmos. Dentre eles, a não realização do DDS diariamente, a falta de divulgação dos membros que compõem a CIPA e a falta de agilidade para sanar riscos relatados chamam mais atenção. Sendo importante destacar que as melhorias propostas para cada, apresentam custo zero ou custos baixos em geral e são de fácil aplicação. Como exemplo, em relação ao DDS, necessita-se apenas de uma maior cobrança para com os técnicos de segurança.

Outro ponto que ficou evidente é o fato de que alguns procedimentos simples e rotineiros, como o simulado de rotas de fuga e o DDS, estão deixando de ser realizados da maneira correta, e que a ausência destes aumenta bastante os riscos diários nas plataformas. Com as indicações de melhoria do Ciclo DMAIC estes processos terão sua periodicidade retomada, reduzindo os riscos automaticamente.

Finalmente, fica comprovado como o Ciclo DMAIC pode auxiliar na otimização do setor de saúde e segurança em plataformas offshore e que é muito válido que as empresas invistam em profissionais do Lean Six Sigma para desenvolver projetos como este.

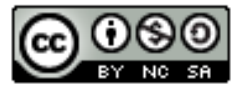


Citação (APA): Lima, F. de O. \& Teles, C. R. (2022). Segurança em plataformas de perfuração e produção de petróleo offshore: aplicação da metodologia Lean Six Sigma. Brazilian Journal of Production Engineering, 8(1), 49-60.

\section{REFERÊNCIAS BIBLIOGRÁFICAS}

Behr, A. et al., (2008). Gestão da biblioteca escolar: metodologias, enfoques e aplicação de ferramentas de gestão e serviços de biblioteca: $C i$. Inf., 37(2), 32-42

Bicheno, J. (2006). The New Toolbox Enxuta. Picsie Books. 152p.

Bôas, M. V. (n.d.). ISO 45001. Recuperado de https://certificacaoiso.com.br/iso-45001/

Buell, R. S. \& Turnipseed, S. P. (2004). Application of Lean Six Sigma in Oilfield Operations. Society of Petroleum Engineers. SPE Production \& Facilities, volume 19.

Cardella, B. (2011). Segurança no trabalho e prevenção de acidentes - uma abordagem holística: segurança integrada à missão organizacional com produtividade, qualidade, preservação ambiental e desenvolvimento de pessoas. São Paulo: Atlas. 254p.

Chessa, C., Magnani, F., \& Fiorido, F., de. (2013). Value Creation Through an Integrated Approach to Performance Improvement. SPE Annual Technical Conference and Exhibition, New Orleans, Louisiana, USA.

Ernst \& Young Terco Brasil. Departamento de Comunicação e Gestão. (2011). Brasil sustentável: perspectivas dos mercados de petróleo, etanol e gás. Brasília: Ernst \&Young Terco.

Hashinaga, E. E. (2019). Uso da metodologia Lean na cadeia upstream de petróleo. Escola Politécnica da Universidade de São Paulo.

IBP. (2019). Número de plataformas no Brasil. Recuperado de https://www.ibp.org.br/observatorio-do-setor/snapshots/numero-de-plataformas-no-brasil$\underline{\text { dez-2019/ }}$

Moraes, G. (2013). Sistema de gestão de riscos: Estudo de Análise de Riscos "Offshore e Onshore". 2. ed. Rio de Janeiro: GVC. 640p.

OIT. (n.d.). Conheça a OIT. Recuperado de https://www.ilo.org/brasilia/conheca-a-oit/lang-$\mathrm{pt} / \mathrm{index} \cdot \mathrm{htm}$

Parmenter, D. (2007). Key Performance Indicators (KPI): Developing, Implementing, and Using Winning KPIs, Hoboken: Wiley.

Peinado, J. \& Graeml, A. R. (2007). Administração da produção: operações industriais e de serviços. Curitiba: UnicenP, 750p.

Rachman, A. \& Ratnayake, R. M. C. (2018). Adoption and implementation potential of the lean concept in the petroleum industry: state-of-the-art. International Journal of Lean Six Sigma, 10(2), 33-52. http://dx.doi.org/10.1108/IJLSS-10-2016-0065

Tønnessen, R. et al., (2015). Application of Lean Principles to Accelerate Project Development. SPE/IADC Drilling Conference and Exhibition. London, United Kingdom.

Udemy. Apostila do Curso: Six-Sigma - Green Belt. [s.d.]. 